\title{
Effective therapeutic interventions for Australian adolescents using alcohol and/ or other drugs: a scoping review
}

\author{
Jennifer Martin ${ }^{*}$ (D), Marg Liddell ${ }^{2}$, Susan Roberts ${ }^{3}$ and Emily Greenwood ${ }^{4}$
}

\begin{abstract}
Background: There are a variety of residential and community service models of therapeutic interventions for people using substances. The focus of much of the currently available research is on adult populations with relatively little known about effective therapeutic interventions for adolescents. The aim of this paper is to identify the most effective therapeutic interventions for Australian adolescents using substances by conducting a systematic scoping literature review.

Methods: We followed the PRISMA guidelines to conduct a systematic scoping review that included searches of nine electronic databases (EMBASE, MEDLINE, EBSCO Host, APA PsycNet, SocIndex, Social Science Abstracts, Proquest Central Informit) and grey literature searches of government department and alcohol and other drugs peak body and service provider websites, Google Scholar and the Cochrane library.

Results: A total of 21 studies were identified. These studies included biological, psychological, social and technological therapeutic interventions targeted at different population groups and different substances. The review findings are limited and should considered with caution due to the inability to disaggregate the combinations of interventions provided and the low quality of most of the studies included.

Conclusions: This scoping review highlights the paucity of quality research on effective therapeutic interventions for Australian adolescents using substances. This is primarily due to the available studies not controlling for all of the therapeutic interventions provided. While there is an evidence-base for some of these interventions, others such as encounter groups and journaling require further and more substantive research for use with adolescents. This is necessary to enable informed service design and delivery decision-making and fiscal accountability.
\end{abstract}

Keywords: Adolescent, Alcohol and other drugs, Substance use, Therapeutic interventions

\section{Background}

Substance use disorders typically have their onset in adolescence so effective treatments are critical for this age group. Adolescents are particularly vulnerable to detrimental physical, psychological and social impacts of drug

\footnotetext{
*Correspondence: jmmartin@swin.edu.au

${ }^{1}$ Social Innovation Research Institute, Faculty of Health Arts and Design, Swinburne University, Swinburne University of Technology, Office AS430 L Internal Mail H31, PO Box 218, Hawthorn, VIC 3122, Australia

Full list of author information is available at the end of the article
}

use. These impacts include significant harm to the developing brain and functional capacity; poor physical, mental, sexual and reproductive health; lowered educational achievement and violence $[1,2]$. In particular, executive brain processes for the achievement of higher order goals are developing during adolescence. This is in the context of increased brain plasticity, sensation seeking and vulnerability to the development of psychopathology. Adolescence can be an uncertain time given the major changes that are occurring physically, psychologically and socially. As a result, interventions suited to adults are

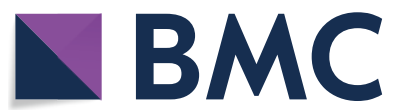

(c) The Author(s) 2020. This article is licensed under a Creative Commons Attribution 4.0 International License, which permits use, sharing, adaptation, distribution and reproduction in any medium or format, as long as you give appropriate credit to the original author(s) and the source, provide a link to the Creative Commons licence, and indicate if changes were made. The images or other third party material in this article are included in the article's Creative Commons licence, unless indicated otherwise in a credit line to the material. If material is not included in the article's Creative Commons licence and your intended use is not permitted by statutory regulation or exceeds the permitted use, you will need to obtain permission directly from the copyright holder. To view a copy of this licence, visit http://creativeco mmons.org/licenses/by/4.0/. The Creative Commons Public Domain Dedication waiver (http://creativecommons.org/publicdomain/ zero/1.0/) applies to the data made available in this article, unless otherwise stated in a credit line to the data. 
not necessarily appropriate for adolescents due to their reduced reasoning capacity and the developmental tasks associated with adolescence including identity and reputation formation and increased autonomy, independence, self-esteem and confidence [3].

The focus of this paper is on how to best respond therapeutically to problematic use of substances by adolescents. There is no agreed universal definition of substance abuse and the terminology used varies and includes terms such as substance use, abuse, misuse, harmful use, hazardous use, substance dependence and addiction. At times, the definitions of these terms are ambiguous creating confusion [4]. For instance, in the latest edition of the Diagnostic and Statistical Manual (DSM5) the American Psychiatric Association uses the term substance abuse [5]. However, in the International Classification of Diseases (ICD-11) the preferred terminology of the World Health Organisation (WHO) is "harmful use" or "hazardous use". For the purpose of this study substance use is the preferred term and it encompasses all types of drug use [6]. The WHO (2020) considers term such as abuse to be disapproving language with the Australian government adopting the language of substance use to support a non-judgmental approach to assist people to disclose usage in a supported environment and to seek appropriate assistance [7].

Therapeutic intervention was defined as an intervention to enhance an adolescent's wellbeing. This may be within a context of voluntary help-seeking by the adolescent or in situations where help has not been actively sought by the adolescent and be provided in person or online [8].

Various explanatory models of drug use exist in alcohol and other drug services including disease, moral and social approaches. Service providers are from diverse backgrounds and use varied treatment approaches that are provided in residential and community settings [9].

The context of Australia was chosen for this scoping review by the funding body who is a not-for-profit provider of alcohol and other drug rehabilitation services to Australian adolescents. This organisation wanted to know what are considered to the most effective therapeutic interventions for Australian adolescents 12 to 17 years of age who are at high risk of drug-related harms due to their substance use. They were particularly interested in what works in the Australian context noting the political, economic and social differences globally. This approach is supported by the joint United Nations/ World Health Organisation SAFER: A Safer World Free from Alcohol Related Harms (2019) initiative that focuses on in-country action within a global context [10]. The focus on Australia was with the understanding that these Australian studies were located within the international literature.
It is anticipated that other countries can also learn from a closer look at the Australian experience given that the types of services offered in Australia are similar to those in other countries around the world including motivational interviewing (MI), cognitive behaviour therapy (CBT) combined with other psycho-social, education and recreation interventions.

\section{Methods}

We used scoping review methodology to achieve our aim of providing a broad rapid overview of a research topic and to identify common themes, issues and gaps in the literature on the most effective therapeutic interventions with a minority of adolescents who have problematic substance use [11]. The review process followed the Cochrane approach and included: (1) selection of search terms and databases, (2) search of refereed and grey literature and hand searching, (3) title and abstract screening, (4) full text review and (5) quality appraisals [12]. Scoping reviews include all relevant literature with the refereed literature consisting of both single studies as well as systematic reviews (Sucharew \& Macaluso) [13]. The literature was mapped, categorized and described to provide evidence of effective therapeutic intervention outcomes.

\section{Research question and definitions}

The aim was to answer the study question: 'What does the evidence in the Australian literature tell us about what are the most effective therapeutic interventions for adolescents, aged 12 to 17 years, using alcohol and/ or other drugs?' The current literature review expands the scope of previous reviews by looking at all reported effective therapeutic interventions for all substance use including both illicit and licit substances (tobacco, pharmaceuticals and illicit drugs) [14]. To the best of the authors' knowledge this is the first scoping review to consider the combination of all substances, misuse and abuse and effective therapeutic interventions for adolescents.

\section{Selection of studies}

The online search databases MEDLINE, EMBASE, APA PsycNet, EBSCO Host, Social Science Abstracts, SocIndex, Informit, Proquest Central, the Cochrane library databases and Google Scholar were chosen due to breadth and relevance to the topic. Targeted browsing was conducted of publications on national, state and territory government and non-government websites. Hand searching of bibliographies and alcohol and other drug training notes was also undertaken. Search terms included 'adolescent' or 'youth' or 'teenage' or 'young' and 'drug' or 'alcohol' or 'substance abuse' and 'recovery program, or 'drug education' or 'intervention', or 'treatment' and 'Australia.' The search date range was set from 
2010 to 2018 (current) with language set as English. This search time-frame was chosen so as to build upon knowledge gained from previous systematic reviews on this topic.

Types of studies included in the review were metaanalyses and literature reviews, controlled experimental studies, before-and-after studies with no control group, observational studies, cohort studies and qualitative studies. The studies needed to provide evidence of the effectiveness of specific therapeutic interventions delivered to adolescents using alcohol and/or other drugs.

\section{Review of studies}

Two authors independently checked all of the studies by title, abstract and full text with a third author available for moderation to reduce researcher bias. The exclusion criteria at the initial screening stage resulted in the removal of papers that were (1) duplicates, (2) not an Australian study, (3) a more recent version was available, (4) published or produced before 2010, (5) inadequate reporting of methods, (6) not specific to adolescents (7) not a therapeutic intervention or (8) not specific to alcohol and other drugs. Duplicate removal included review of the individual studies and studies included in the systematic reviews.

\section{Data analysis}

Thematic analysis was used to interpret and categorise the data into therapeutic intervention categories according to intervention type and therapeutic outcomes [15]. The data were analysed and reported according to study design, year of study, type and length of therapeutic interventions, sample size, inclusion criteria, age of participants, gender and therapeutic outcomes. Two authors categorised the data independently and then jointly to present an accurate representation of the entire dataset. Multi-level synthesis was used to integrate the quantitative and qualitative study data [16].

\section{Assessment of bias}

Quality assessments were conducted on all of the included studies to evaluate methodological strength and risk of bias, using the recommended validated tools suited to the particular type of study. The Cochrane Collaboration's Tool was used to assess controlled trials [17]; the Critical Appraisal Skills Program (CASP) Qualitative Checklist was used to assess qualitative studies including aims, methodology, design, recruitment, data collection, relationship between researcher/s and participants, ethical issues, data analysis, findings and significance [18], and the Study Quality Assessment Tools from the National Heart, Lung and Blood Institute were used to assess systematic reviews and meta-analyses, cross-sectional and observation cohort studies [19]. Systematic reviews were assessed on the adequacy of the formulation of the research question, clarity of inclusion and exclusion criteria, search strategies, independent review by two or more researchers of abstracts and full-text, internal validity, listing of included studies and key features, and publication bias [19].

\section{Results}

A total of 21 studies was included comprising 3,493 participants (excluding the literature review samples). Due to only studies on effective therapeutic interventions being included some substances, such as tobacco, were not present in the study findings. The search strategy revealed 2121 texts for the initial screening of title and abstract with 730 articles progressing to full text review (see Fig. 1).

The final studies included were 17 experimental studies and 4 non-experimental studies. Most studies provided multiple interventions but did not evaluate the efficacy of all of these, thereby restricting the attribution of improved outcomes to a specific intervention. Studies were grouped according to focus of the intervention as (1) individual [20-26, 29-41]; (2) family [20, 22, 25-28]; (3) organisational [20-22, 25-28, 34, 39, 40] and (4) multiple interventions [20-22, 25, 26, 35, 40]. The following interventions were reported as producing effective therapeutic outcomes with further details of all studies provided in Table 1.

\section{Individual}

Individual interventions included counselling and mentoring. The combination of cognitive behaviour therapy (CBT), motivational interviewing (MI) and mindfulness delivered over 10 sessions was found to result in sustained improvements in anxiety and depression, coping skills and functioning with decreased substance use [29]. The addition of CBT and MI to standard care of case management and brief $\mathrm{MI}$ (BMI) resulted in significant reductions in depression and cannabis use with sustained increases in motivation and socialisation [30]. The combined three strategies of BMI, coping skills training and psycho-education with the addition of personalised assessment feedback were found to be more effective than a brief assessment and general information only in reducing alcohol and substance use intake and psychological distress [31]. A range of focused psychological strategies over 5 sessions resulted in reduced psychological distress compared with other treatment and no treatment [23]. A median number of 


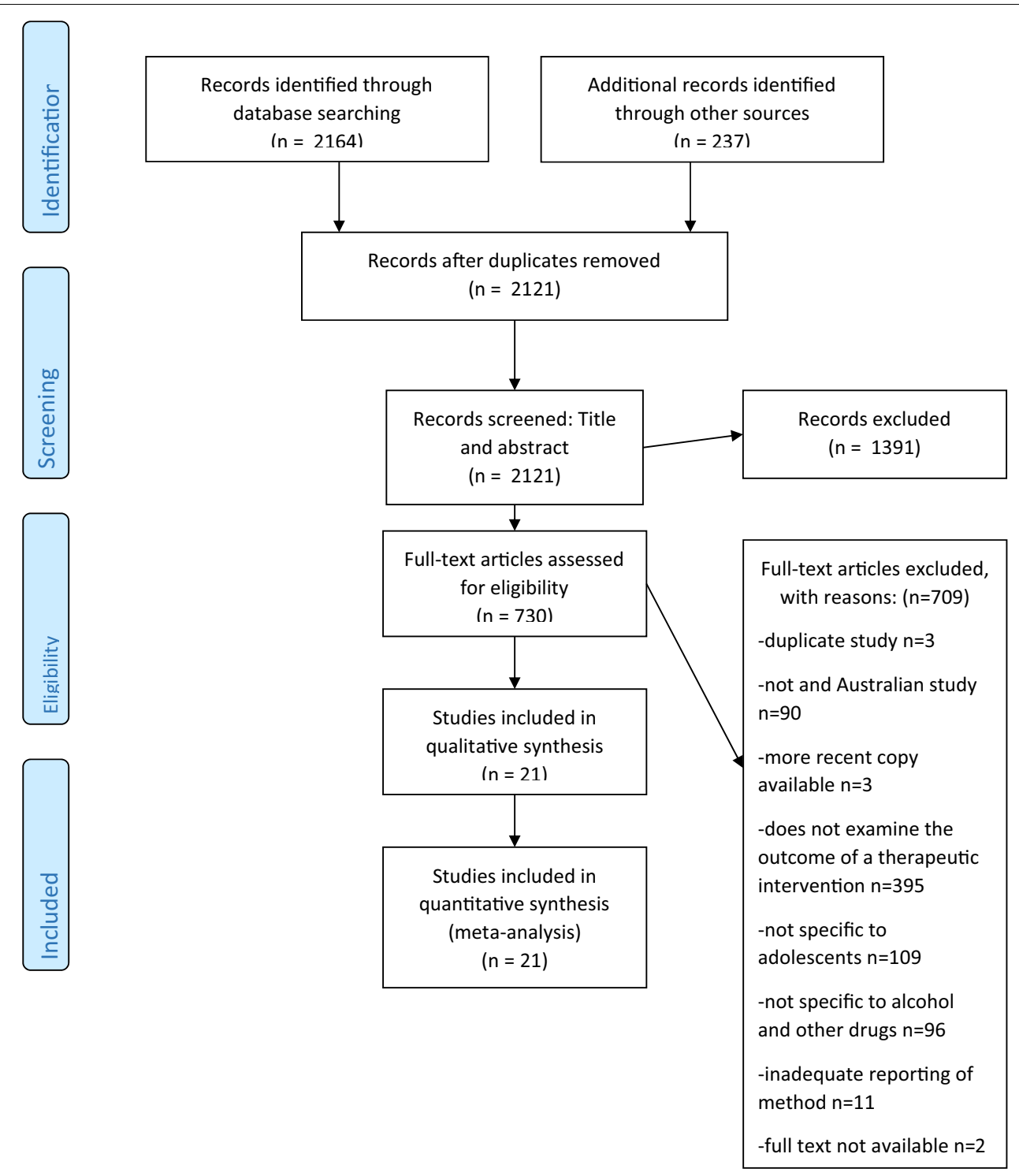

Fig. 1 PRISMA Flow Diagram [36] search strategy results

3 counselling sessions delivered over a 2-year period resulted in a decrease in the frequency and amount of cannabis use and increased life satisfaction [36].

\section{Family}

Family-based interventions included family, therapy and family counselling. A systematic review of familybased interventions for alcohol misuse and alcoholrelated harm in Indigenous communities found that family-based interventions led to positive effects in individual and family functioning and coping and decreased alcohol consumption [28].

\section{Organisational}

One effective organisational intervention was continuing care and community integration in a hospital setting. A study in four emergency departments of usual care, compared with brief advice and a referral linkage to an external alcohol and other drug (AOD) service, found a reduced number of mental health and AOD presentations in emergency departments (ED) for noninjecting drug use [39].

\section{Multiple interventions}

Some studies had multiple interventions including combinations of individual and family work, education and training, recreation, peer groups, community and 


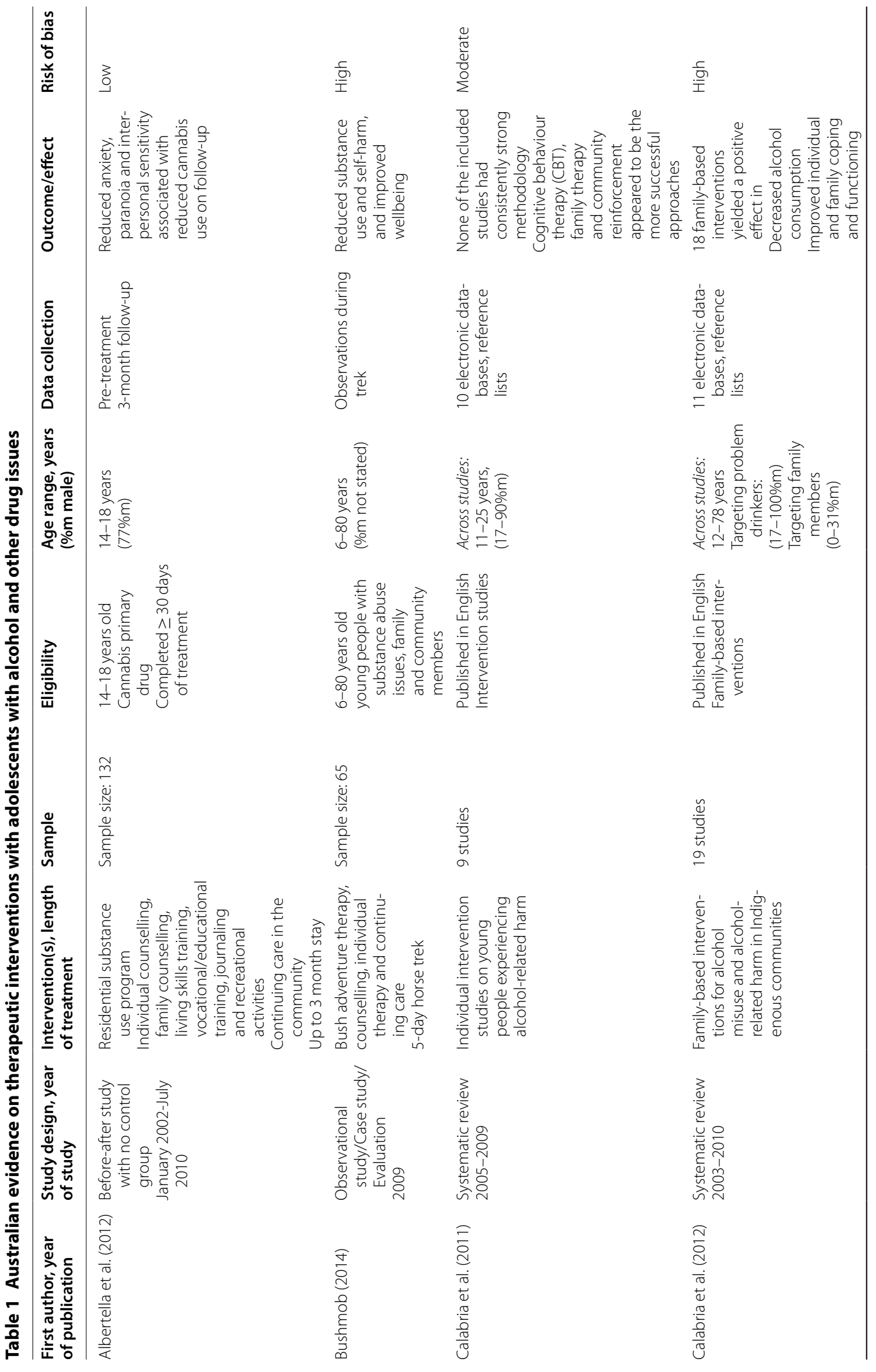




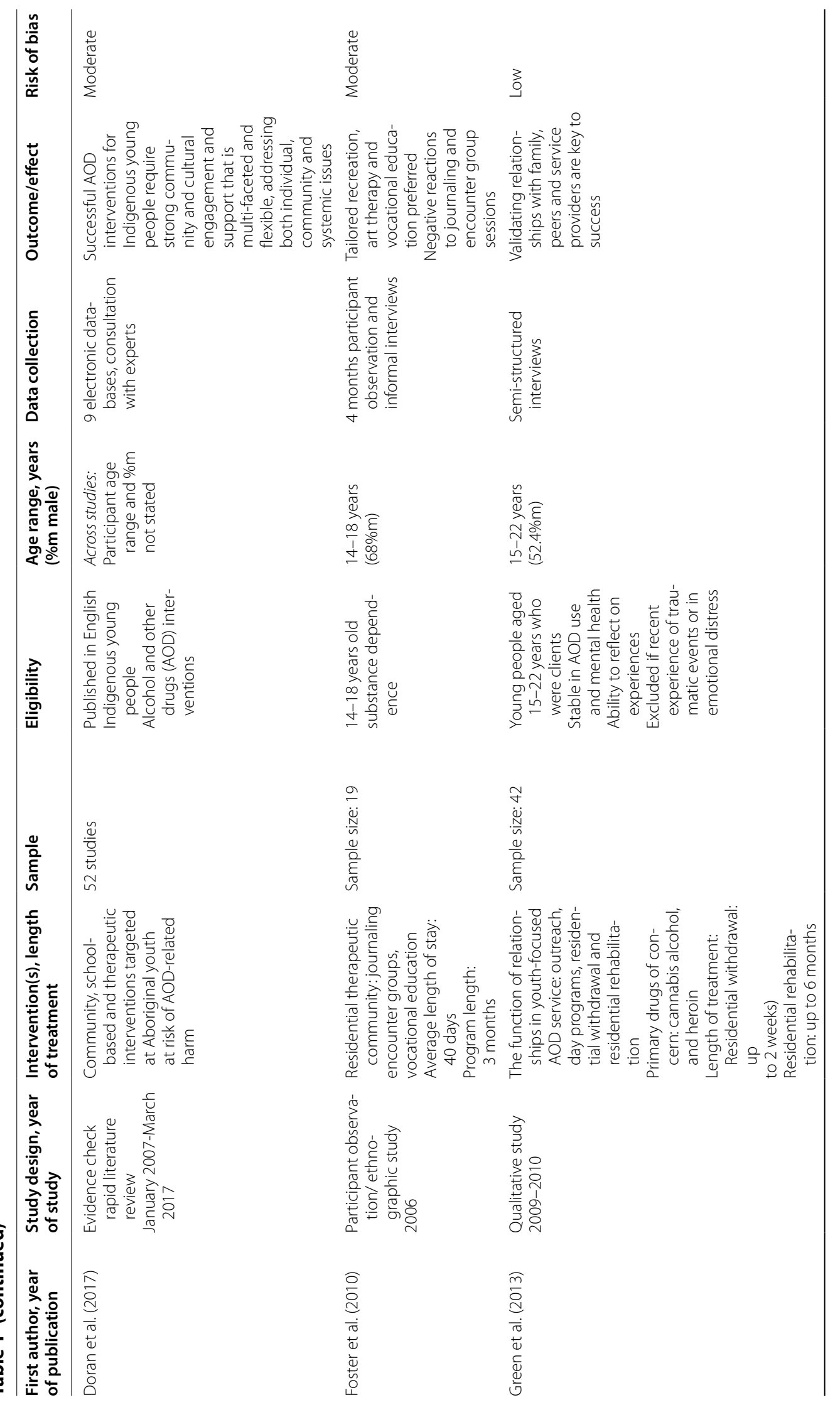




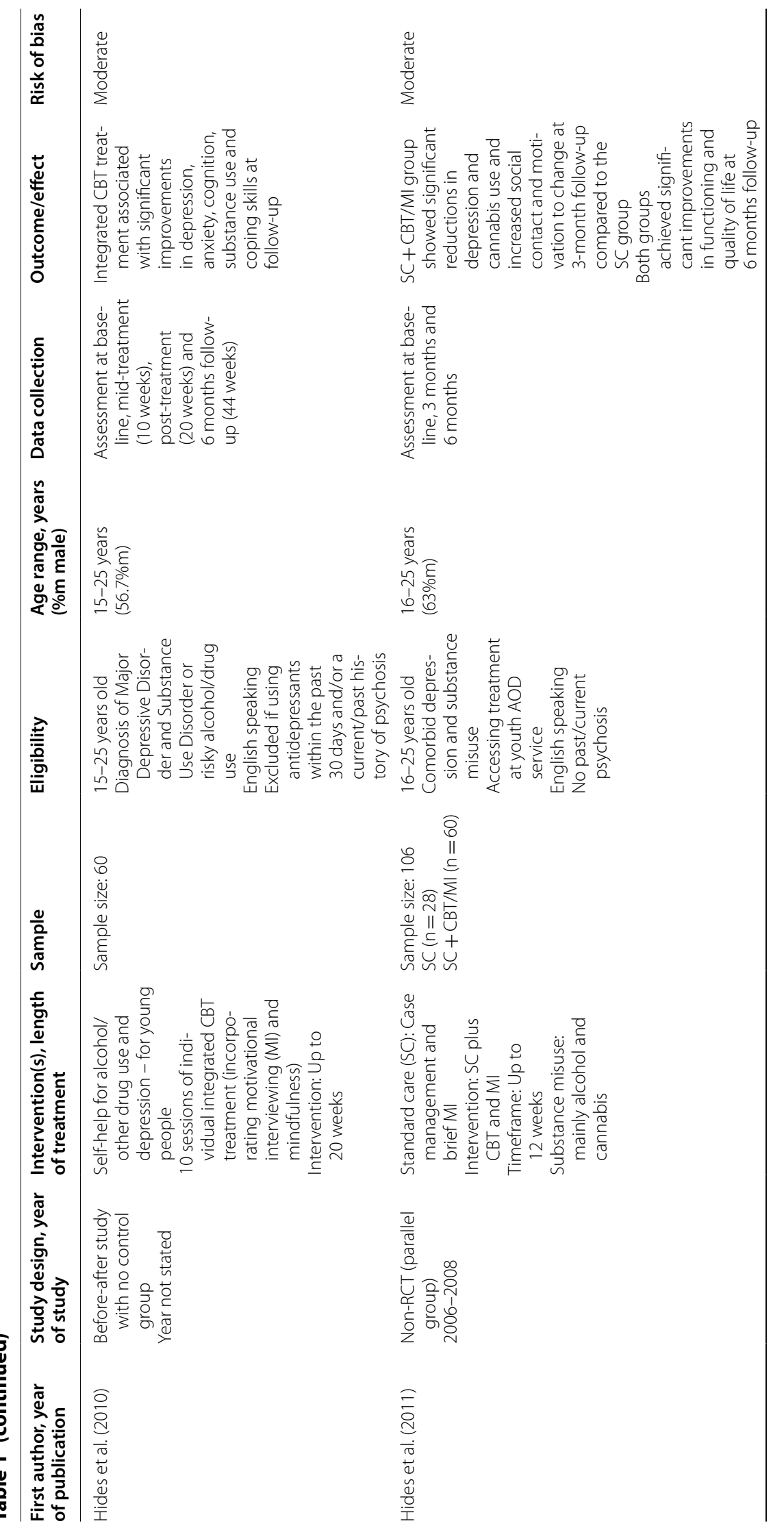




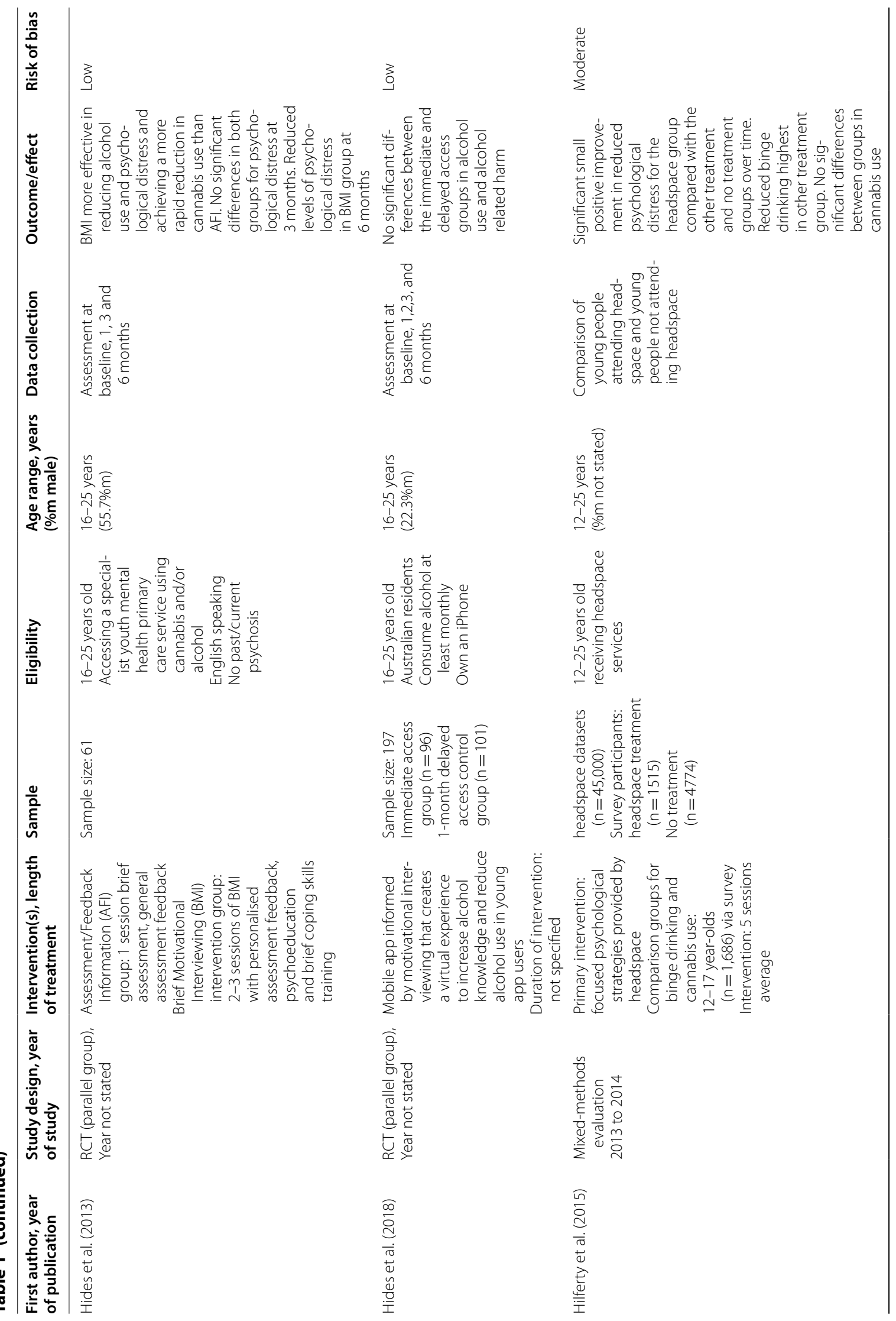




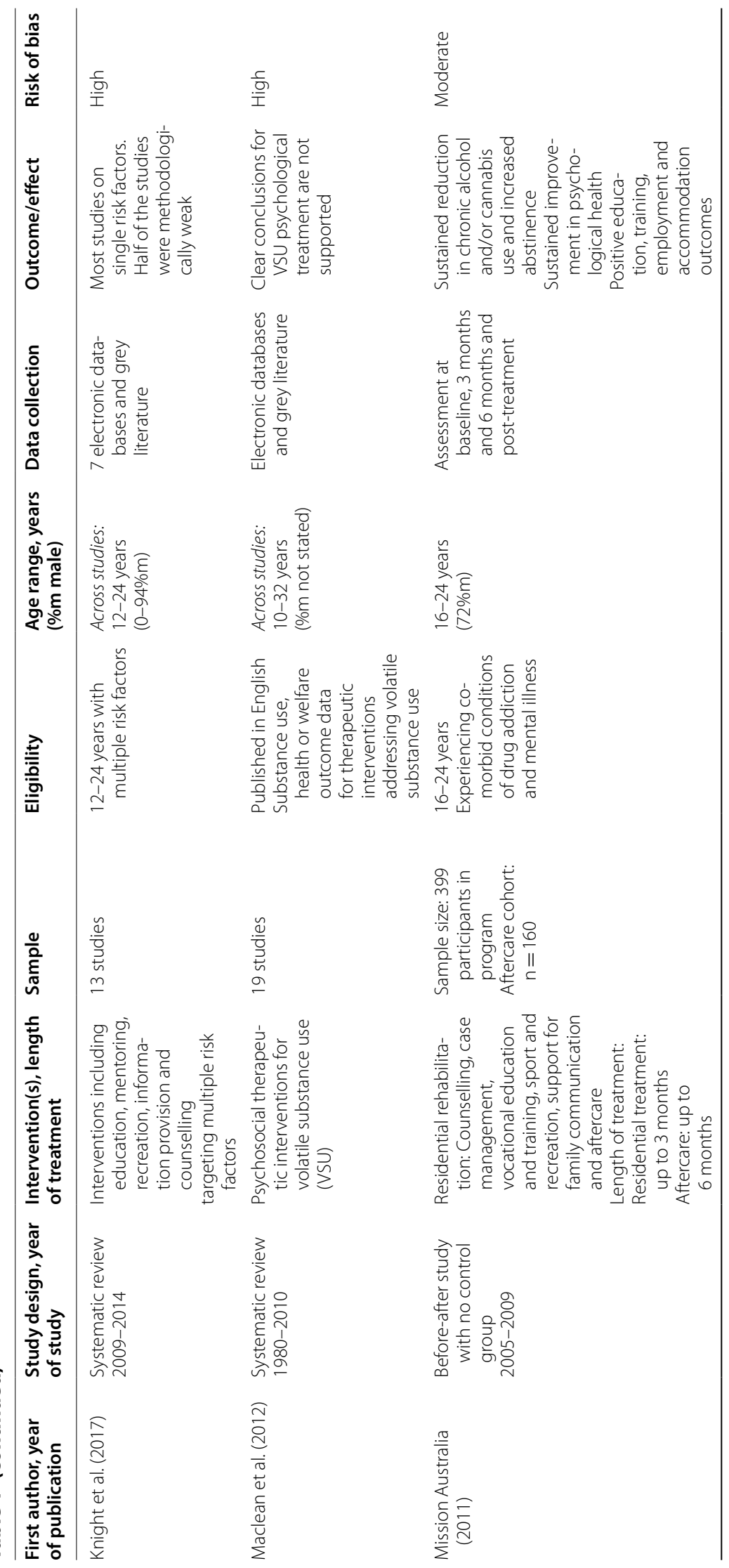




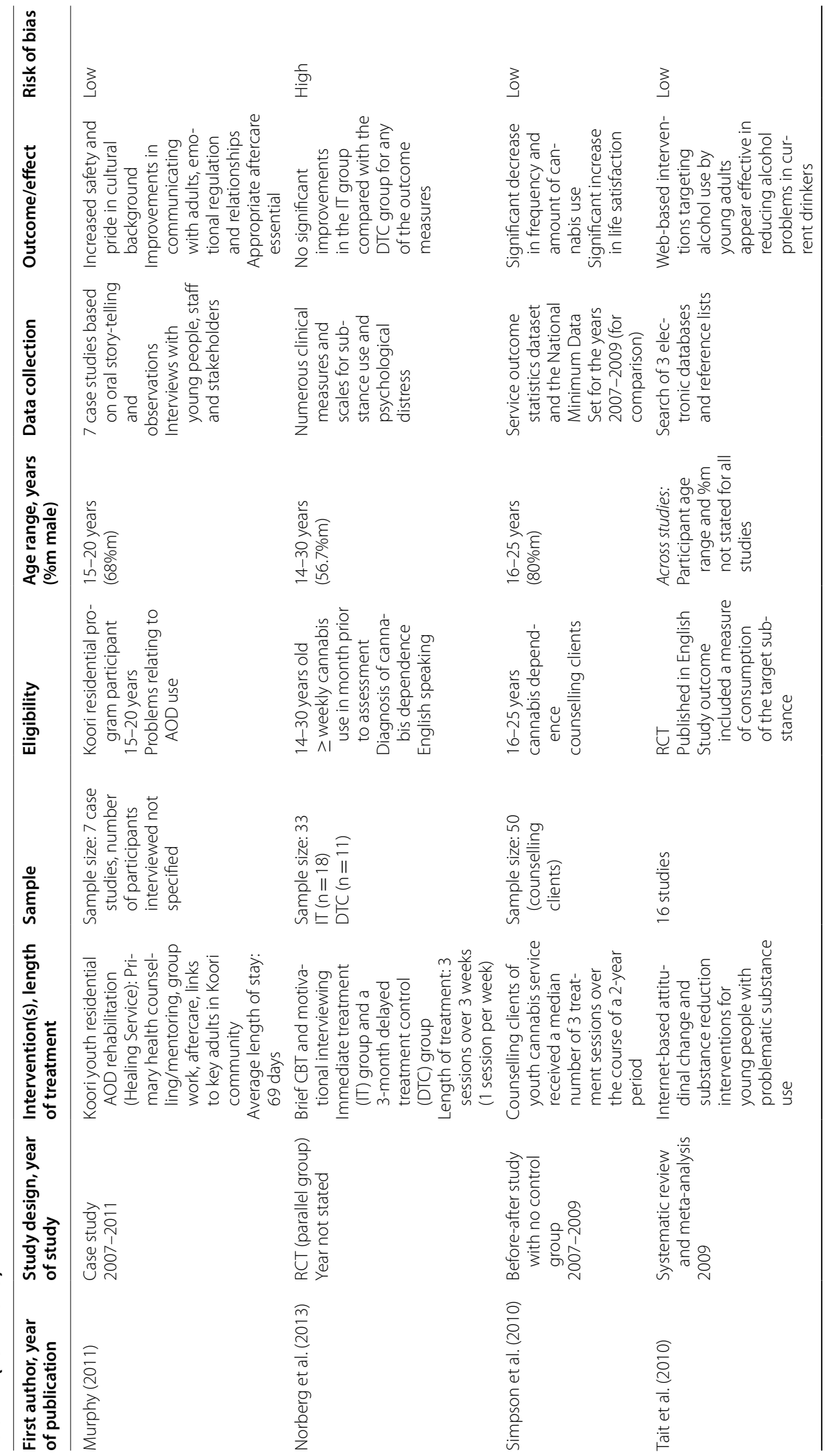




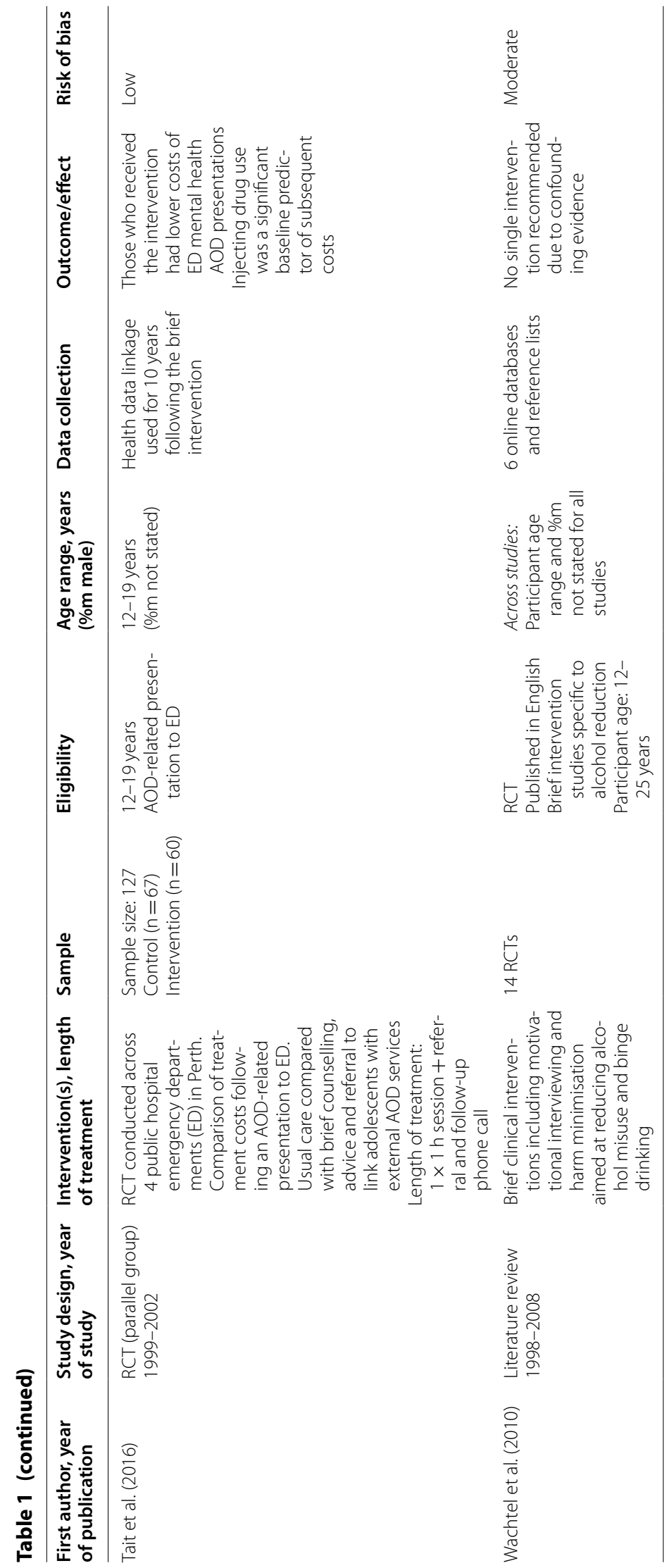


cultural engagement including mentoring. Two studies in residential programs that provided individual and family counselling, vocational education and training and recreation activities found sustained outcomes for decreased substance use, improved mental health and enhanced interpersonal relationships [20, 25]. Bush adventure therapy combined with counselling and continuing care resulted in reduced substance use and self-harm, and improvements in wellbeing [22]. An observational study in a residential therapeutic community found individually tailored recreation, art therapy and vocational education to be more effective than journaling and encounter groups [35]. Validating relationships with family, peers and service providers was found to be the key to the success of a service that provided a range of interventions in residential, day and outreach programs [40]. A study in a residential Koori youth rehabilitation (healing) service providing individual, family, group and community aftercare services found these interventions resulted in increased safety, pride in culture, and improvements in relationships and emotional regulation. Appropriate aftercare was considered essential [26]. A literature review found successful AOD interventions targeted at Aboriginal young people included flexibility, strong engagement with culture and community and addressed individual, community and systemic issues [21].

\section{Limitations}

As mentioned earlier, this scoping review was limited according to study location and timeframe. The reliability of the findings is limited due to the low quality of studies, in terms of risk of bias and the study of interventions provided in conjunction with other interventions that were not evaluated at the same time. The non-blinding of participants in some of the controlled experimental studies [23, 30-32, 37, 39] could have biased participant responses. Participants may have felt pressured to respond positively to remain in the treatment program, not lose privileges and maintain positive relationships with staff.

\section{Discussion}

This scoping review identified a range of individual, family, organisational and multiple combined interventions for working with adolescents using substances. The findings reveal the effectiveness of particular groupings (not all) of interventions in residential and after-care settings. CBT and MI were found to be effective together [37] and when combined with mindfulness [29], or psychoeducation, coping skills training and personalised assessment feedback [31] or case management [30]. Three of these were brief interventions (BI) between 2-3 sessions [29, 31, 37]. These findings support other research on the effectiveness of BI for this population group [41]. The effectiveness of individual CBT and MI interventions is well documented in evidence-based international research [42].

The study findings highlight important issues related to interventions with no evidence-base such as journaling, recreation and adventure activities, and encounter groups with adolescents. An intervention warranting further investigation is journaling. For instance, journaling was in a multiple intervention study [20] that produced significant outcomes. However, in another study journaling received a strong negative reaction from some adolescents [35]. Peer feedback encounter groups also warrant closer investigation as this same study found that a group with adolescents providing direct feedback to each other resulted in social ostracization [35].

Encounter groups are frequently used in adult residential substance use services. However, the use of these groups with adolescents requires further scrutiny due to adolescents developmental needs related to reasoning capacity, identity formation and relationships [3]. Other studies found groupwork to be beneficial [22, 26, 36]. The types of groups varied and were provided as part of a package of interventions. Building positive and affirming relationships with adolescents was considered essential for effective treatment outcomes. Notions of success were variable across the studies with improvement considered a success regardless of whether or not the adolescent completed the treatment program. The importance of continuing care was highlighted with some adolescents having multiple separate periods of engagement with a service/s over time.

\section{Future research, practice and policy considerations}

Further research and evaluation is required on all therapeutic interventions currently used with young people using substances. In particular, interventions that do not have an evidence-base for use with adolescents such as encounter groups and journaling require closer scrutiny. It is recommended that intervention costings information be provided in future studies to inform public health resource allocation decision-making.

\section{Conclusion}

The main finding of this scoping review is that there is currently no evidence base for some of the therapeutic interventions frequently provided to adolescents by alcohol and other drugs service providers. There is no evidence that services such as encounter groups, that are used widely in adult alcohol and other drugs services, are directly transferable to the adolescent population. This is particularly so due to the unique developmental stage and associated tasks at adolescence disrupted by 
substance use. Nonetheless, the studies examined in this scoping review, report a number of combined interventions that are considered effective. The lack of evidence for all of these interventions, when delivered in combination, hinders the ability to assess intervention specific benefits.

\section{Acknowledgement}

This study was supported by the Salvation Army Tasmania Division.

\section{Competing interests}

The authors declare that they have no competing interests.

\begin{abstract}
Author details
${ }^{1}$ Social Innovation Research Institute, Faculty of Health Arts and Design, Swinburne University, Swinburne University of Technology, Office AS430 L Internal Mail H31, PO Box 218, Hawthorn, VIC 3122, Australia. ${ }^{2}$ Social and Global Studies Centre, RMIT University, GPO Box 2476, Melbourne, VIC 3001, Australia. ${ }^{3}$ Swinburne University of Technology, Swinburne Library C/-AS430 L Internal Mail H31, PO Box 218, Hawthorn, VIC 3122, Australia. ${ }^{4}$ Swinburne University of Technology, Office: C/-AS430 I Internal Mail H31, PO Box 218, Hawthorn, VIC 3122, Australia.
\end{abstract}

Received: 31 August 2020 Accepted: 29 November 2020

Published online: 07 December 2020

\section{References}

1. Nathan S, Rawstone P, Hayen A, Bryant J, Baldry E, Ferry M, et al. Examining the pathway for young people with drug and alcohol dependence: a mixed method design to examine the role of a treatment programme. BMJ Open. 2016;6:e010824.

2. Patel V, Flisher A, Hetrich S, McGorry P. Mental health of young people: a global public-health challenge. Lancet. 2007;369:1302-13.

3. Luna B. Adolescent development of brain systems supporting cognition and motivation. J Am Acad Child Adolesc Psychiatry. 2018;57(10):S271.

4. Shiel, M. Medical definition of substance abuse. In: MedicineNet 2020 https://www.medicinenet.com/substance_abuse/definition.htm. Accessed 20 Nov 2020.

5. American Psychiatric Association. Diagnostic and statistical manual of mental disorders. 5th ed. Washington DC: APA; 2013.

6. World Health Organisation. Lexicon of alcohol and drug terms. Geneva: WHO; 2020.

7. Australian government. Pregnancy care guidelines: 15 Substance Use Canberra: Department of Health; 2019.

8. Psychology Today. Therapeutic intervention. Sussex Directories Inc. 2020. https://www.psychologytoday.com/au/therapy-types/therapeutic-inter vention. Accessed 20 Nov 2020.

9. Barnett A, Hall W, Fry C, Dilkes-Frayne E, Carter A. Implications of treatment providers varying conceptions of the disease model of addiction: a response. Drug Alcohol Rev. 2018;37:729-30.

10. World Health Organisation. The SAFER technical package: Five areas of intervention at national and subnational levels. Geneva: WHO; 2019.

11. Noyes J, Popay J, Pearson A, Hannes K, Booth A. Qualitative research and Cochrane reviews. In: Higgins J, Green S, editors. Cochrane Handbook for Systematic Reviews of Interventions Version 5.1.0. London: The Cochrane Collaboration; 2011. p. 571-587.

12. Armstrong R, Hall BJ, Doyle J, Waters E. Cochrane update 'Scoping the scope' of a Cochrane review. J Public Health. 2011;33:147-50.

13. Sucharew $H$, Macaluso M. Methods for research evidence synthesis: the Scoping Review approach. J Hosp Med. 2019;14(7):416-8.

14. Australian Institute of Health and Welfare. National drug survey household survey 2016. Canberra: Australian government; 2017.

15. Clarke V, Braun V. Thematic analysis. J Positive Psychol. 2017;12(3):297-8.

16. Moher D, Liberati A, Tetzlaff J, Altman DG, The PRISMA Group. Preferred Reporting Items for Systematic Reviews and Meta-Analyses: The PRISMA Statement. PLoS Med. 2009;6(7): 1000097.
17. Higgins J, Altman D, Gotzsche P, Juni P, Moher D, Oxman A, et al. The Cochrane Collaboration tool for assessing bias in randomised trials. BMJ. 2011:343:1-9.

18. CASP. NHS Critical Appraisal Skills Programme (CASP): appraisal tools. Oxford, United Kingdom: NHS Public Health Resource Unit; 2018.

19. National Heart, Lung and Blood Institute. Study Quality Assessment Tools. Bethesda, MD, United States of America: Department of Health and Human Services; 2018.

20. Albertella L, Norberg M. Mental health symptoms and their relationship to cannabis use in adolescents attending residential treatment. J Psychoactive Drugs. 2012;44:381-9.

21. Doran C, Kinchin I, Bainbridge R, McCalman J, Shakeshaft A. Effectiveness of alcohol and other drug interventions in at-risk Aboriginal youth: an evidence check rapid review brokered by the Sax Institute for the NSW Ministry of Health. New South Wales: Sax Institute; 2017.

22. Bushmob. Bushmob Incorporated: Submission to the Inquiry into the harmful use of alcohol in Aboriginal and Torres Strait Islander communities. Best Practise treatments and support for minimising alcohol misuse and alcohol-related harm. Alice Springs, Northern Territory: Bushmob Incorporated: 2014

23. Hilferty F, Cassells R, Muir K, Duncan A, Christensen D, Mitrou F, et al. Is headspace making a difference to young people's lives? Final Report of the independent evaluation of the headspace program. Sydney, New South Wales: Social Policy Research Centre, University of New South Wales; 2015.

24. Knight A, Shakeshaft A, Havard A, Maple M, Foley C, Shakeshaft B. The quality and effectiveness of interventions that target multiple risk factors among young people: a systematic review. Aust N Z J Public Health. 2017:41:54-60.

25. Australia M. Triple Care Farm: a safe place for change: 1989-2009/Mission Australia: Sydney. New South Wales: Mission Australia; 2011.

26. Murphy B. Final report of the Koori Youth Alcohol and Drug Healing Service: YSAS \& Ngwala. Melbourne, Victoria: Youth Research Centre, The University of Melbourne; 2011

27. Calabria B, Shakeshaft A, Havard A. A systematic and methodological review of interventions for young people experiencing alcohol-related harm. Addiction. 2011;106:1406-18.

28. Calabria B, Clifford A, Shakeshaft A, Doran C. A systematic review of family-based interventions targeting alcohol misuse and their potential to reduce alcohol-related harm in Indigenous communities. J Stud Alcoh Drugs. 2012;73:477-88.

29. Hides L, Carroll S, Catania L, Cotton SM, Baker A, Scaffidi A, Lubman D. Outcomes of an integrated cognitive behaviour therapy treatment program for co-occurring depression and substance misuse in young people. J Affect Disord. 2010;121:169-74.

30. Hides L, Elkins KS, Scaffidi A, Cotton SM, Carroll S, Lubman D. Does the addition of integrated cognitive behaviour therapy and motivational interviewing improve the outcomes of standard care for young people with comorbid depression and substance misuse? Med J Austr. 2011;195:31-7.

31. Hides L, Carroll S, Scott R, Cotton S, Baker A, Lubman D. Quik fix: A randomized controlled trial of an enhanced brief motivational interviewing intervention for alcohol/cannabis and psychological distress in young people. Psychother Psychosom. 2013;82:122-4.

32. Hides L, Quinn C, Cockshaw W, Stoyanov S, Zelenko O, Johnson D, et al. Efficacy and outcomes of a mobile app targeting alcohol use in young people. Addict Behav. 2018;77:89-95.

33. Wachtel T, Staniford M. The effectiveness of brief interventions in the clinical setting in reducing alcohol misuse and binge drinking in adolescents: a critical review of the literature. J Clin Nurs. 2010;19:605-20.

34. MacLean S, Cameron J, Harney A, Lee N. Psychological therapeutic interventions for volatile substance use: a systematic review. Addiction. 2012;102:278-88.

35. Foster M, Nathan S, Ferry M. The experience of drug-dependent adolescents in a therapeutic community. Drug Alcohol Rev. 2010;29:531-9.

36. Simpson M, Howard J, Rodas A, Kalmar D. FYRST STOP Youth Cannabis Clinic: Evaluation using routinely collected data. In: NCPIC Bulletin. Sydney New South Wales: National Cannabis Prevention and Information Centre. University of New South Wales 2010.

37. Norberg M, Battisti R, Olivier J, Copeland J, Hermens D, Hickie I. A brief intervention for help-seeking young adult and adolescent cannabis users 
with psychiatric comorbidity: findings and treatment manual. Sydney, New South Wales: National Cannabis Prevention and Information Centre, University of New South Wales; 2013.

38. Tait R, Christensen H. Internet-based interventions for young people with problematic substance use. Med J Austr. 2010;192(11):S15-21.

39. Tait R, Teoh L, Kelty E, Geelhoed E, Mountain D, Hulse G. Emergency department based intervention with adolescent substance users: 10 year economic and health outcomes. Drug Alcohol Depend. 2016;165:168-74.

40. Green R, Mitchell P, Bruun A. Bonds and bridges: perspectives of serviceengaged young people on the value of relationships in addressing alcohol and other drug issues. J Youth Stud. 2013;16:421-40.
41. Tait R, Hulse G. A systematic review of the effectiveness of brief interventions with substance using adolescents by type of drug. Drug Alcohol Rev. 2010;22:337-46.

42. Dobson D, Dobson K. Evidence-based practice of cognitive-behavioral therapy. 2nd ed. New York and London: The Guilford Press; 2017.

\section{Publisher's Note}

Springer Nature remains neutral with regard to jurisdictional claims in published maps and institutional affiliations.
Ready to submit your research? Choose BMC and benefit from:

- fast, convenient online submission

- thorough peer review by experienced researchers in your field

- rapid publication on acceptance

- support for research data, including large and complex data types

- gold Open Access which fosters wider collaboration and increased citations

- maximum visibility for your research: over 100M website views per year

At BMC, research is always in progress.

Learn more biomedcentral.com/submissions 